\title{
Abdominal wall implantation of hepatocellular carcinoma
}

\author{
Ali Aldahham ${ }^{1}$, Shurooq Boodai ${ }^{2}$, Adel Alfuderi ${ }^{1}$, Ahmad Almosawi ${ }^{1}$ and \\ Sami Asfer*1,3
}

\begin{abstract}
Address: ${ }^{1}$ The Liver Unit, Departments of Surgery, Mubarak Al-Kabeer Hospital, Kuwait, ${ }^{2}$ Department of Pathology, Mubarak Al-Kabeer Hospital Kuwait and ${ }^{3}$ Department of Surgery, Faculty of Medicine, P.O.Box 24923, Safat-13110, Kuwait

Email: Ali Aldahham - alied1971@hotmail.com; Shurooq Boodai - shurooq@hotmail.com; Adel Alfuderi - abuhamad119@hotmail.com; Ahmad Almosawi - dralmosawi@yahoo.com; Sami Asfer* - Asfer@edu.kw.com

* Corresponding author
\end{abstract}

Published: 08 October 2006

World Journal of Surgical Oncology 2006, 4:72 doi:10.1 186/1477-7819-4-72

This article is available from: http://www.wjso.com/content/4/I/72

(C) 2006 khalifa et al; licensee BioMed Central Ltd.

This is an Open Access article distributed under the terms of the Creative Commons Attribution License (http://creativecommons.org/licenses/by/2.0), which permits unrestricted use, distribution, and reproduction in any medium, provided the original work is properly cited.
Received: 13 March 2006

Accepted: 08 October 2006

\begin{abstract}
Background: Percutaneous fine needle aspiration cytology (FNAC) became a popular method for diagnosis of hepatic masses. Abdominal wall implantation from FNAC is rare.

Case presentation: We report a female patient who presented with a right upper abdominal wall mass 3 years following a fine needle aspiration cytology (FNAC) and resection of a solitary hepatocellular carcinoma (HCC) from the liver. The mass proved to be a metastatic HCC; it was locally resected with safety margins. To date (20 months later) she remains well with no recurrence.

Conclusion: Implantation of tumor cells after FNAC for HCC is rare, but can happen. The availability of dynamic imaging of the liver should reduce the need for this technique in the diagnostic workup of patients suspected of having HCC
\end{abstract}

\section{Background}

Percutaneous fine needle aspiration cytology (FNAC) became a popular method for diagnosis of hepatic masses. The reported mortality rate following this procedure ranges between $0.006 \%$ and $0.03 \%$. The associated morbidity is $0.05 \%-0.18 \%$, this includes: hemoperitoneum, hematoma, local infection, bile peritonitis and anaphylactic shock [1]. In this report we present a rare case of abdominal wall implantation of hepatocellular carcinoma 3 years following FNAC and resection of the primary lesion.

\section{Case presentation}

A 61-year-old female, known to suffer from chronic hepatitis C (Child Pugh A), presented in Jan 2001 to another hospital complaining of abdominal pain. CT-Scan of the abdomen showed a solitary $5 \times 5 \mathrm{~cm}$ mass in segment VII of the liver. Fine needle aspiration cytology (FNAC) showed features consistent with HCC. AFP level at the time was normal $2.23 \mathrm{ng} / \mathrm{ml}$ (normal $<5.6 \mathrm{ng} / \mathrm{ml}$ ). She traveled abroad (outside Kuwait), underwent resection of the tumor and returned back to Kuwait. A brief report stated that the tumor was resected from segment VII with about $1.5 \mathrm{~cm}$ safety margin with an uneventful postoperative course. Histopathology of the original tumor proved to be a well differentiated HCC with clear margins and no vascular invasion.

Upon return to Kuwait, she was under the care of the hepatologist who treating her chronic hepatitis with Pegelated Interferon and Ribaverin for 6 months. Unfortunately she remained HCV positive. 
In Oct. 2004, three years following her original surgery, she was referred to the Liver Unit, Mubarak Al-Kabeer Hospital with an abdominal wall mass of one-year duration. On physical examination an obvious $7 \times 5 \mathrm{~cm}$ smooth oval mass was seen in the right upper quadrant at the lateral border of her previous right subcostal scar. Clinically the mass seemed to be within the abdominal wall and the skin over it was free. CT scan of the abdomen showed a round well defined enhancing soft tissue density mass measuring $11 \times 5 \times 5 \mathrm{~cm}$ within the anterior abdominal wall with no intra-abdominal extension or skin infiltration (Figure 1). The liver was free except from signs of previous surgery in segment VII. Tumor markers were: AFP $6.23 \mathrm{ng} / \mathrm{ml}$ (normal < $5.6 \mathrm{ng} / \mathrm{ml}$ ), CEA $1.5 \mathrm{ng} /$ $\mathrm{ml}$ (normal < $6.9 \mathrm{ng} / \mathrm{ml}$ ) and CA19-9 15.9 (normal < 43 $\mathrm{ng} / \mathrm{dl}$ ). FNAC from this mass, was consistent with metastatic HCC (Figure 2). En-bloc resection of the mass (including the mass, overlying skin, abdominal wall mus- cles and peritoneum) was performed under general anesthesia with primary closure. Histopathology of the removed specimen confirmed implantation of HCC in the abdominal muscles with free surgical margin and no peritoneal penetration (Figure 3 ). The patient had an uneventful recovery and was discharged home on the $7^{\text {th }}$ postoperative day.

To date, 20 months since resection of the metastatic mass, she remains well with normal AFP and liver functions and no evidence of recurrence in the liver or abdominal wall.

\section{Discussion}

Implantation of hepatocellular carcinoma to the abdominal wall after percutaneous fine needle aspiration cytology is rare ranging from $1.4 \%$ to $3.4 \%$ [1]. The reported risk factors for tract implantation after FNAC include: the size of the tumor, degree of histological differentiation of

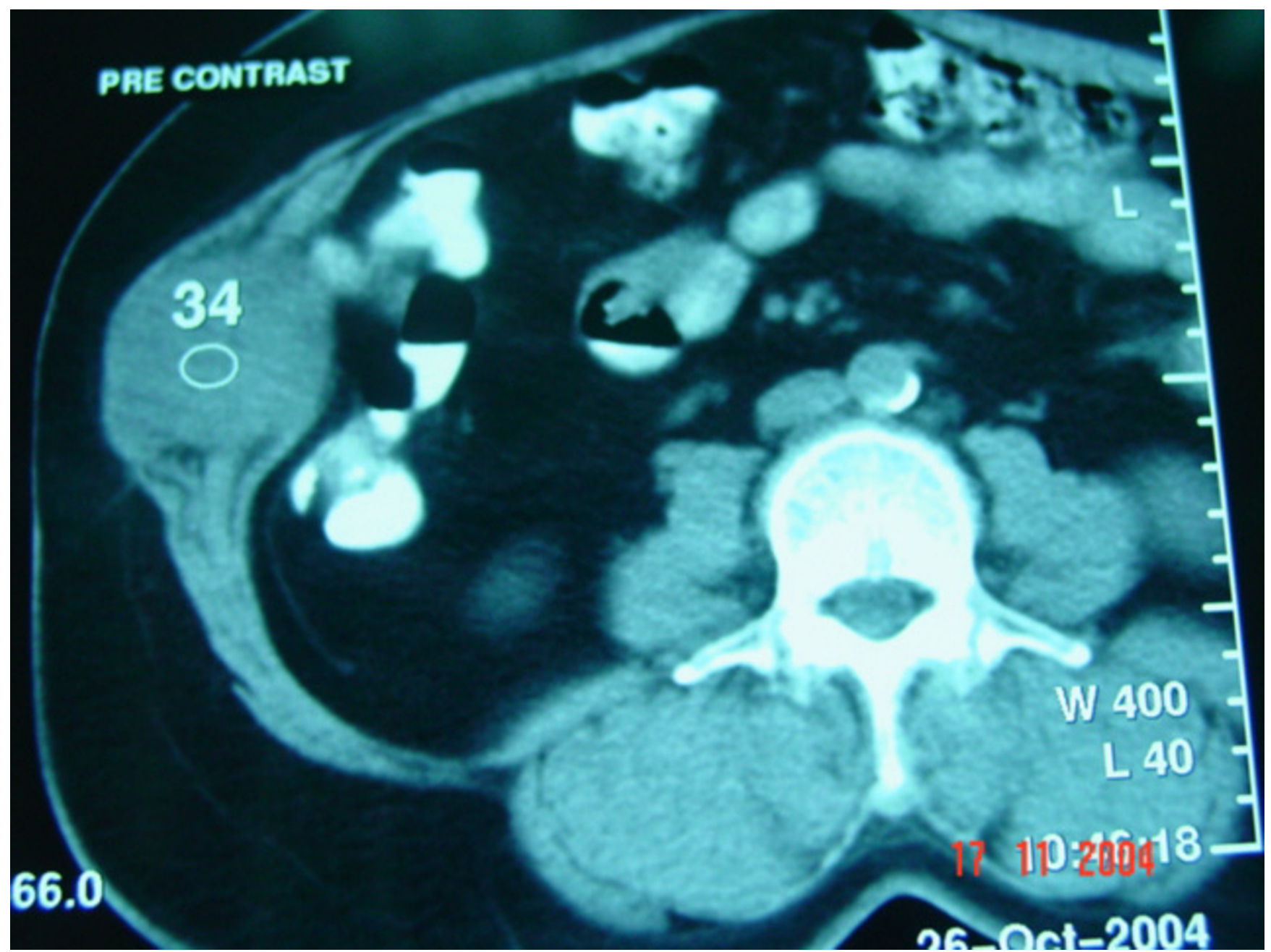

\section{Figure I}

CT-Scan of the abdominal wall, shows the the mass within the abdominal wall muscles in the right hypochondrium with no intrperitoneal extension. 


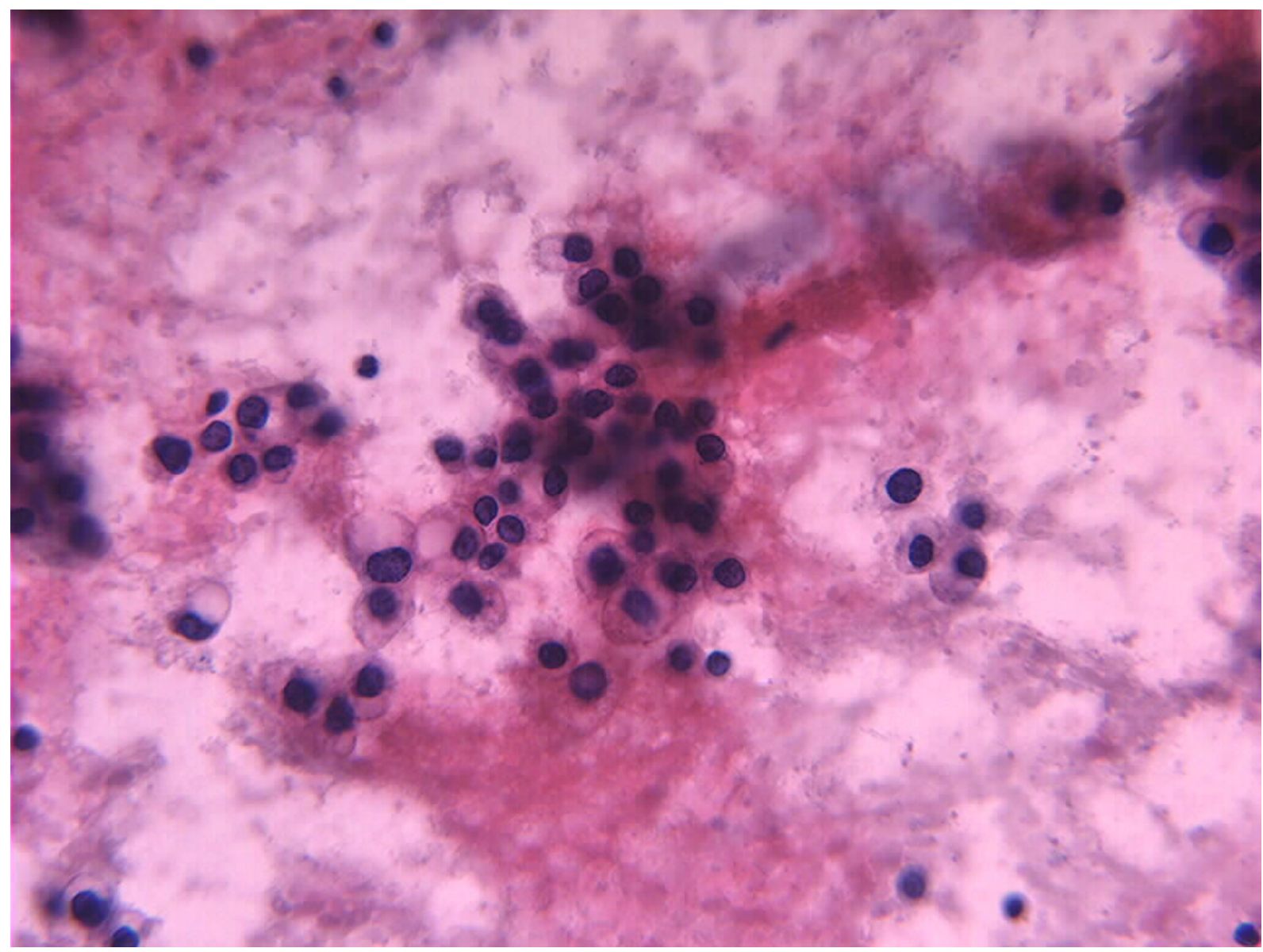

\section{Figure 2}

FNAC (Fine Needle Aspiration Cytology) from the mass shows polygonal cells forming microacini at places. Features consistent with Hepatocellular Carcinoma. (Papanicolaou Stain × 400)

HCC, a thin layer of liver parenchyma along the needle tract and the number of needle passes [1-3]. It has been shown that repeated attempts with the needle during FNAC are associated with higher chance of implantation to the abdominal wall [1]. However, implantation was reported even after a single pass [4]. There seems to be a greater chance of implantation with end-cutting biopsy needles [5].

Most HCC patients present with large and poorly differentiated tumors; they have a short survival time. Whereas patients with small, resectable and well differentiated tumors live longer and hence the probability of detecting tumor implantation in the abdominal wall after FNAC is perhaps higher in this group. The patient presented in this report had a solitary small well differentiated tumor and is still alive 5 years since her liver tumor was resected with normal liver function and no recurrence.

The tumor implantation reported in this patient, may be due to FNAC or perhaps due to spillage from the tumor during surgery. We do not have the exact details of the surgical procedure as it was done in a different country. However, the brief operative report presented to us did not indicate any surgical mishaps.

Malignant cell seeding is a well known complication of diagnostic and therapeutic procedures in HCC [6]. Denton et al indicated that there are no prospective studies about this issue; there is only small series and case reports in the literature [7]. They indicate that there is an underestimation of the risk of tumor implantation in HCC and 


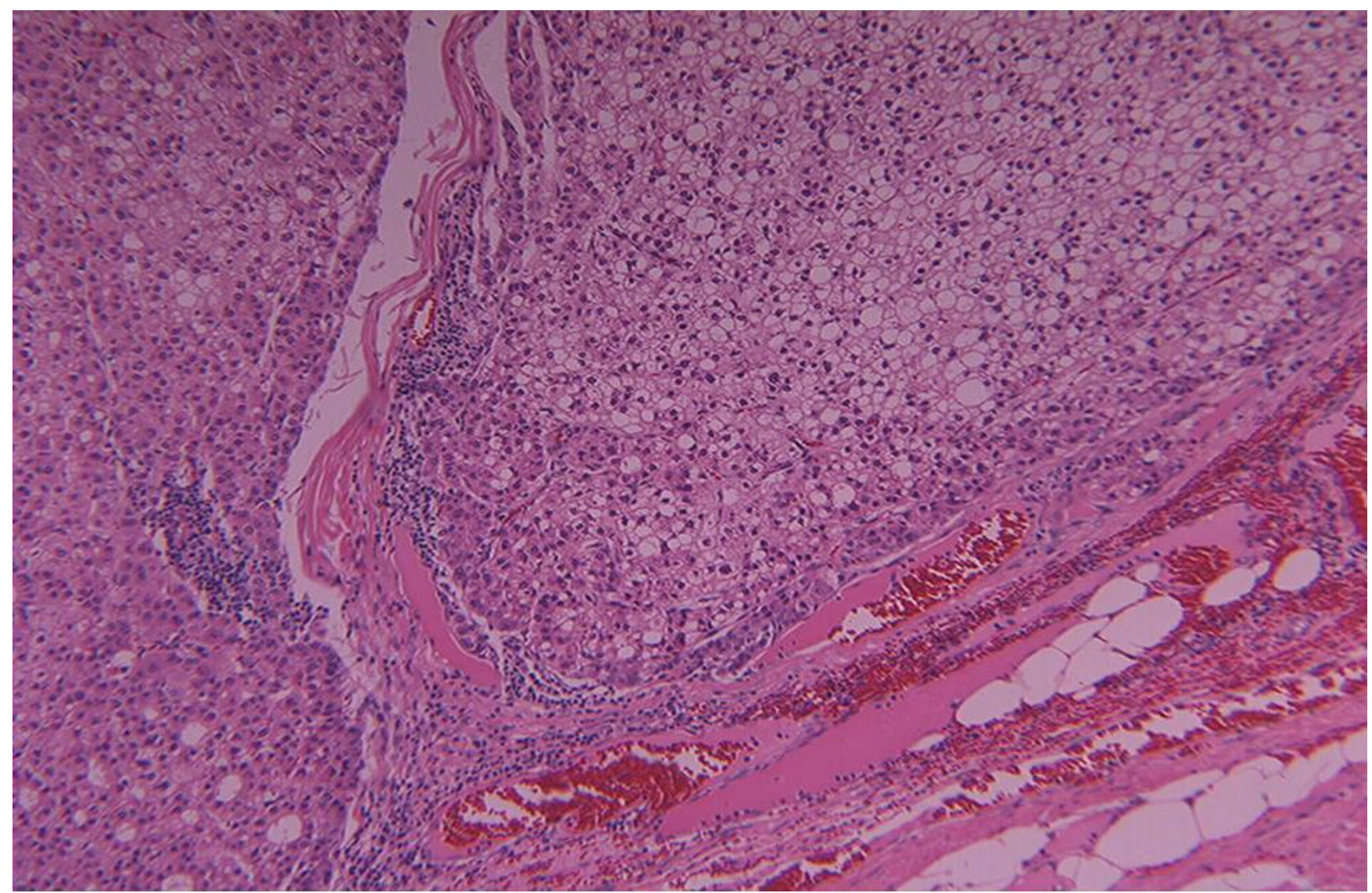

\section{Figure 3}

Histopathological examination of the excised mass. Shows that the tumour is made of thick hepatocyte cell plates with foci of acinar formation from the margins. (H\&E stain, I0x HPF)

stated that many are not diagnosed or even not reported [7].

The recent consensus meeting of the EASL(European Association for the study of the liver) and the AASLD (American association for the surgery of liver disease) in Barcelona 2005 indicated that a diagnosis of HCC in the setting of cirrhosis can confidently be made by two dynamic imaging techniques if both show increased vascularity characteristic of HCC. The panel accepted the concept of "washout" in the portal venous phase of a CT-Scan as specific for HCC; this is shown as hypo-attenuation in the late portal phase of a liver lesion which was hypervascular in the hepatic arterial phase [8]. In addition the panel agreed that an AFP of $>400 \mathrm{ng} / \mathrm{ml}$ together with only one typical imaging technique is specific for HCC [8]. Therefore, the introduction of dynamic liver studies by multidetector CT-Scan or MRI would allow clinicians to diagnose most cases of HCC with confidence without FNAC. However few atypical cases do exist and these would definitely require FNAC. The policy adopted in our
Liver Unit is in accordance with the 2005 Barcelona criteria.

\section{Conclusion}

Implantation of tumor cells after FNAC for HCC is rare, but can happen. The availability of dynamic imaging of the liver should reduce the need for this technique in the diagnostic workup of patients suspected of having HCC.

\section{Competing interests}

The author(s) declare that they have no competing interests.

\section{Authors' contributions}

AAk: Study design, data collection, data analysis and manuscript drafting. SB: Histopathology studies and final reporting. AA: Literature review and manuscript drafting. AAf: Data collection and literature review. SA: Idea originator, Critical reviewing of manuscript and final writing

All authors have read and approved the manuscript 


\section{Acknowledgements}

The patients consent was obtained for publication of this case report

\section{References}

I. Kim SH, Lim HK, Lee WJ, Cho JM, Jang HJ: Needle -tract implantation in hepatocellular carcinoma: frequency and CT findings after biopsy with a 19.5-gauge automated biopsy gun. Abd Imaging 2000, 25:246-250.

2. Sakurai M, Okamura J, Seki K, Kuroda C: Needle tract implantaion of hepatocellular carcinoma after percutanous liver biopsy. Am J Surg Pathol 1983, 7:191-195.

3. Yamada N, Shinzawa H, Ukai K, Wakabayashi H, Togashi H, Takahashi T, Seo N, Ishiyama S, Tsukamoto M, Fuyama S: Subcutaneous seeding of small hepatocellular carcinoma after fine needle aspiration biopsy. J Gastroenterol Hepatol 1983, 8:195-198.

4. Soyer P, Pelage JP, Dufresne AC, Boudiaf M, Kardache M, Dahan H, Rymer R: CT of abdominal wall implantation metastases after abdominal percutaneous procedures. J Computer Assist Tomography 1998, 22:889-893.

5. Huang GT, Sheu JC, Yang PM, Lee HS, Wang TH, Chen DS: Ultrasound - guided cutting biopsy for the diagnosis of hepatocellular carcinoma - a study based on 420 patient. J Hepatol 1996, 25:334-338.

6. Stigliano R, Burroughs AK: Should we biopsy each liver mass suspicious for HCC before liver transplantation?-No please don't. J Hepatology 2005, 43:563-568.

7. Denton KJ, Cotton DW, Nakielny RA, Goepel JR: Secondary tumor deposits in needle biopsy tracks: an underestimated risk? J Clin Pathol 1990, 43:83.

8. Bruix J, Sherman M: Management of hepatocellular carcinoma. Hepatology 2005, 42: I 208-1236.

Publish with Bio Med Central and every scientist can read your work free of charge

"BioMed Central will be the most significant development for disseminating the results of biomedical research in our lifetime. "

Sir Paul Nurse, Cancer Research UK

Your research papers will be:

- available free of charge to the entire biomedical community

- peer reviewed and published immediately upon acceptance

- cited in PubMed and archived on PubMed Central

- yours - you keep the copyright

Submit your manuscript here:

http://www.biomedcentral.com/info/publishing_adv.asp 